\title{
O PAPEL POLÍTICO DOS AGENTES PÚBLICOS NA COMPRA DIRETA DA AGRICULTURA FAMILIAR EM SÃO BERNARDO DO CAMPO
}

\author{
THE POLITICAL ROLE OF PUBLIC AGENTS IN DIRECT PROCUREMENT FROM FAMILY AGRICULTURE IN SÃO BERNARDO \\ DO CAMPO
}

\section{EL PAPEL POLÍTICO DE LOS ACTORES PÚBLICOS EN LA COMPRA DIRECTA DE LA AGRICULTURA FAMILIAR EN SÃO BERNARDO DO CAMPO}

\section{RESUMO}

0 presente artigo analisa o papel dos atores governamentais, ou seja, do alto escalão, dos dirigentes públicos e da burocracia, na implementação da compra direta da agricultura familiar para a merenda escolar no município de São Bernardo do Campo, que alcançou o direcionamento de $100 \%$ dos recursos fornecidos pelo Fundo Nacional de Desenvolvimento da Educação (FNDE) para as cooperativas de agricultores. A análise da experiência está baseada no período de sua implementação (de 2009 a 2012), e pode ser caracterizada como qualitativa e de campo. 0 texto aborda uma discussão teórica sobre 0 papel dos atores na implementação das políticas públicas, seguida de uma contextualização sobre a experiência de São Bernardo do Campo e da análise do papel dos atores em sua implementação. 0 artigo conclui que a atuação discricionária e politicamente orientada da equipe envolvida na implementação foi fundamental para atender às diretrizes nacionais.

PALAVRAS-CHAVE: Implementação, políticas públicas, compras públicas, agricultura familiar, São Bernardo do Campo.

Deloise de Fátima Bacelar de Jesus - deloise.jesus@gmail.com

Mestre em Ciências Humanas e Sociais pela Universidade Federal do ABC - Santo André - SP, Brasil

Tamara Ilinsky Crantschaninov - tami.crants@gmail.com

Doutoranda em Administração Pública e Governo pela Fundação Getúlio Vargas, Escola de Administração de Empresas de São Paulo

- São Paulo - SP, Brasil

Submetido 21.03.2017. Aprovado 11.08.2017

Avaliado pelo processo de double blind review.

DOI: http://dx.doi.org/10.12660/cgpc.v22n73.67208 


\begin{abstract}
The present article analyzes the role of government actors, i.e., high-ranking officials, government leaders and bureaucracy, in implementing direct procurement from family agriculture for school meals in the municipality of São Bernardo do Campo, SP, Brazil, which met the allocation target of $100 \%$ of the funds provided by the National Education Development Fund (FNDE) for farmers' cooperatives. The analysis of the experience is based on its implementation period (2009 to 2012), and can be characterized as qualitative and field research. The text presents a theoretical discussion about the role of actors in the implementation of public policies, followed by a contextualization of the experience in São Bernardo do Campo and an analysis of the role of actors in its implementation. The article concludes that the implementation team's discretionary and politically oriented action was fundamental to meet national guidelines.
\end{abstract}

Keywords: Implementation, public policy, public procurement, family agriculture, São Bernardo do Campo.

\title{
Resumen
}

Este artículo examina el papel de los actores gubernamentales, es decir, del alto mando, de los líderes públicos y de la burocracia en la ejecución de la compra directa de la agricultura familiar para el comedor escolar en São Bernardo do Campo, que logró dirigir $100 \%$ de los recursos proporcionados por el Fondo Nacional de Desarrollo de la Educación - FNDE a las cooperativas de agricultores. El análisis de la experiencia se basa en el período de su implementación (2009 a 2012), y puede caracterizarse como cualitativo y de campo. El texto aborda una discusión teórica sobre el papel de los actores en la implementación de politicas públicas, seguida de una contextualización de la experiencia del municipio de São Bernardo do Campo (SP) y del análisis del papel de los actores en su implementación. El artículo concluye que el trabajo discrecional y políticamente orientado del equipo involucrado en la implementación fue esencial para cumplir las directrices nacionales.

Palabras clave: Implementación, políticas públicas, compras públicas, agricultura familiar, São Bernardo do Campo.

\section{INTRODUÇÃO}

Especialmente a partir do processo nacional de redemocratização e da reforma do Estado na década de 1990, a busca pela eficiência e proximidade com os cidadãos contribuiu com o movimento de descentralização, que fez com que as esferas locais, especialmente as administrações municipais, passassem a ser as principais responsáveis pela operação de fato das políticas sociais (Farah, 2000). Assim, entre as fases utilizadas para estudar o instrumento analítico conhecido como ciclo das políticas públicas, é possível afirmar que a etapa da implementação é realizada de maneira precípua pela esfera municipal, de acordo com o pacto federativo instituído pela Constituição Federal de 1988. Seja porque o congresso formulou uma nova diretriz nacional para o funciona- mento da administração pública, seja porque os ministérios ou secretarias estaduais instituíram determinações como pressuposto para o repasse de recursos, ou por quaisquer outras formas de coordenação governamental, quase sempre os municípios não têm oportunidade de determinar a agenda, formular ou elaborar os aspectos estruturantes de diversos temas das políticas públicas.

Por essa característica federativa, é comum que os municípios tenham que se adaptar e garantir a implementação das legislações e diretrizes impostas pelos outros entes federados. A dinâmica da implementação envolve desde regulamentações para as especificidades locais (decretos e portarias) até a adaptação de estruturas administrativas, alocação, sensibilização e treinamento de pessoal. Dessa maneira, o alinhamento e 
a disposição dos diferentes atores públicos com a política pública em questão se fazem elementos essenciais para o sucesso do processo de implementação municipal de diretrizes de outras esferas de governo.

Dado esse contexto, o presente artigo busca contribuir com os estudos a respeito de implementação de políticas públicas abordando o papel do alto escalão, dos dirigentes públicos e da sensibilização da burocracia por meio da análise de um caso de implementação em esfera municipal de uma legislação nacional. O objetivo do estudo é analisar o caso da implementação da Lei $\mathrm{n}$. 11.947 (2009), que determina a contratação direta de cooperativas de agricultores familiares para a merenda escolar, no município de São Bernardo do Campo, à luz da teoria sobre implementação de políticas públicas, em especial o papel dos agentes implementadores. A análise apresentada está baseada na pesquisa realizada ao longo dos anos de 2013 e 2014 para a elaboração de dissertação (Jesus, 2014) que analisou o período de implementação da experiência (de 2009 a 2012).

O artigo é constituído por três seções, além desta introdução e de suas conclusões. A primeira seção discute a bibliografia a respeito da etapa da implementação no ciclo de políticas públicas e do papel dos atores governamentais para o sucesso da implementação. A segunda descreve a política de compra direta da agricultura familiar, a metodologia empregada na pesquisa de campo realizada em São Bernardo do Campo sobre o contexto da implementação dessas compras no município, as características dos atores públicos responsáveis pela implementação, os desafios e esforços empreendidos para a im- plementação, assim como seus resultados e desdobramentos. A terceira seção analisa a importância e o papel dos atores governamentais, tanto no sucesso da fase inicial da implementação da experiência quanto no declínio do ritmo e na qualidade do favorecimento às cooperativas de agricultores familiares. Finalmente, as conclusões do artigo sustentam que a atuação discricionária e politicamente orientada da equipe envolvida na implementação foi fundamental para atender às diretrizes nacionais.

\section{O PODER DE AGÊNCIA DOS ATORES NA IMPLEMENTAÇÃO DE POLÍTICAS PÚBLI- CAS}

As teorias clássicas a respeito do ciclo de políticas públicas (Kingdon, 1984) consideram um fluxo linear entre as fases de formulação, implementação e avaliação, com uma aparente racionalidade nessa sequência. Dessa maneira, a partir das diretrizes formuladas pelos atores responsáveis pela primeira fase do ciclo, caberia aos implementadores somente as seguir a fim de atingir os resultados esperados pelos atores interessados em seus resultados. A avaliação seria responsável por verificar se a implementação se desviou ou não do plano inicial, e, caso se desviasse, a política pública seria considerada fracassada por não cumprir com os ensejos de seus formuladores.

Apesar de ser amplamente difundida e utilizada no ensino de Administração Pública, essa abordagem apresenta diversos desafios de aplicabilidade. O primeiro é que ela considera que a política pública é dada num cenário estático, um jogo de uma rodada só, sem possibilidade de mudanças posteriores. Ainda, pressupõe-se que os formuladores 
têm acesso a todas as informações necessárias para a composição da estratégia de formulação, e seu diagnóstico está correto em todas as vezes, o que é faticamente impossível. A sociedade é composta de inúmeras incertezas, dada a alta complexidade das interações sociais. Ela também ignora que os responsáveis pela implementação de determinada política têm vontade própria, que pode diferir da dos formuladores.

A abordagem processualista, por sua vez, acredita que existe uma retroalimentação entre as fases de implementação e formulação da política pública (Barrett, 2004). Isso quer dizer que, enquanto a política é implementada, é possível promover ajustes no plano formulado originalmente, de modo que corresponda, de maneira mais fidedigna, à realidade. Os desafios encontrados durante a implementação permitem a correção de rota e incorporam novos elementos à formulação, tornando a política pública mais rica.

Na prática, o que existe é um processo de negociação entre implementadores e formuladores - a implementação é mais um jogo do que a aplicação de um plano, ao pé da letra. Contudo, esse jogo só é possível de ser compreendido a partir da transposição do modelo racional de burocracia, consagrado por Weber (1982), que entende o burocrata como sujeito não interessado, particularmente, na condução da política pública por caminhos diferentes do programado. O modelo processual entende, ao contrário, que o burocrata é autointeressado, ou seja, pode ter opiniões divergentes das do formulador da política pública, e, sendo responsável por sua implementação, poderá se utilizar da sua discricionariedade para alterar o plano original.

A compreensão da discricionariedade do burocrata é fundamental para entender o poder de agência do implementador, ou seja, seu poder de agir de acordo com seu autointeresse. A discricionariedade é a margem de abertura interpretativa com que cada implementador conta no momento de sua ação. A depender das estruturas de controle e autonomia, a discricionariedade pode variar para mais ou menos. Em alguns casos, é positivo que o burocrata conte com o maior grau de discricionariedade possível - por exemplo, um médico que precisa se utilizar de seus conhecimentos específicos para uma operação cirúrgica. Em outros, como no caso de aplicação de padrões de vigilância, quanto menos discricionariedade, melhor.

Contudo, a maior parte das políticas sociais não se encontra em nenhum desses extremos, e o poder de agência do implementador depende da fluidez de cada modelo de política pública, e também do papel que este ocupa na estrutura de comando da política. Sobre o assunto, Bonis e Pacheco (2010) consideram a necessidade de elucidar 0 papel do que chamam de dirigente público, "pessoas que ocupam cargos no alto escalão governamental, com responsabilidade significativa pelas políticas públicas e pelo desenho das organizações públicas, respondendo diretamente aos ministros ou secretários de Estado" (pp. 329-330). Ou seja, são funcionários administrativos, mas que devem utilizar seus conhecimentos e responsabilidades para direcionar a política pública, conforme as orientações políticas de seus superiores. Eles são responsáveis por garantir a executabilidade da ideia original da política pública, pela qual esta foi formulada. Por 
isso, precisam gozar de discricionariedade para realizar ajustes durante sua implementação. Bonis e Pacheco (2010) inclusive destacam que uma das principais divergências entre o dirigente público e o burocrata é seu nível de discricionariedade: enquanto a do dirigente público é média, a do burocrata deve ser baixa. Além disso, os dois perfis têm motivações distintas: enquanto o dirigente público se move pela maximização dos resultados esperados, o burocrata deve se atentar à aplicação impessoal das regras. Os autores ainda ressaltam as diferenças de recursos de poder (conhecimento técnico do burocrata e conhecimento gerencial do dirigente público), o acesso à posição (concursos e processos seletivos para o burocrata e indicação para o dirigente público), a permanência no cargo (longa para o burocrata e curta para o dirigente público) e o grau de responsividade (baixa para o burocrata e média-alta para o dirigente público).

Ao definir a divisão entre os perfis, é possível compreender melhor onde deve residir o poder de agência do agente público e sua discricionariedade. A partir da experiência de São Bernardo do Campo na implementação da compra direta da agricultura familiar, será discutido como esse poder se manifesta por meio das ações dos funcionários públicos daquele município.

\section{A IMPLEMENTAÇÃO DA COMPRA DIRE- TA DA AGRICULTURA FAMILIAR EM SÃO BERNARDO DO CAMPO}

O favorecimento da agricultura familiar por meio do uso do Poder de Compra do Estado é uma das estratégias do Programa Federal “Fome Zero", criado em 2003, e está relacionado com distintas políticas públicas (Silva,
Grossi, \& França, 2010). Há várias possibilidades de aquisição pública de alimentos, como é o caso das refeições hospitalares, dos restaurantes populares e da merenda escolar. No entanto, como a atual estrutura de compras públicas ainda é bastante complexa, os agricultores familiares possuem grande dificuldade de vender seus produtos para o governo por meio de licitações tradicionais, por exemplo pela falta de conhecimento do modo de operação das complexas regras dos editais de licitação, do acesso aos sistemas eletrônicos de licitação e da obtenção de toda a gama de documentações que são exigidas nesse modelo de contratação.

O movimento de uso do Poder de Compra do Estado dos anos 2000 (Jesus, 2013) resultou em um conjunto de ações que favorecem a agricultura familiar nos processos de compras públicas federais, a exemplo do Programa de Aquisição de Alimentos (PAA) e da possibilidade presente na Lei Federal $n$. 11.947 (2009). Ambos os programas permitem que as aquisições sejam feitas por meio de processos de chamadas públicas, e não de licitação. Essa possibilidade retira grande parte das necessidades de apresentação de documentos e facilita o processo, de modo que apenas os agricultores familiares individualmente ou em organizações (cooperativas e associações) possam fornecer para essas aquisições.

A Lei n. 11.947 (2009) trata, entre outros temas, de definições para os repasses do Fundo Nacional de Desenvolvimento da Educação (FNDE) para a merenda escolar. A legislação explicita quais são os parâmetros para a aquisição de merenda, quais os objetivos do Programa Nacional de Alimentação Escolar (PNAE) e qual a lógica da transfe- 
rência federal (para os estados, municípios e distrito federal) dos recursos do PNAE por meio do FNDE. Entre suas diretrizes, a lei, em seu 140 artigo, determina que, entre os recursos recebidos por meio do FNDE, no mínimo, 30\% deles devem ser destinados à aquisição de produção proveniente da agricultura familiar. Os mecanismos para a operação desse dispositivo, tais como as determinações do chamamento público e as regras para a aquisição dos agricultores, foram explicitados nas Resoluções FNDE n. 38 (2009) e n. 26 (2013).

A compra direta da agricultura família promovida pela legislação avança por estimular a aquisição de alimentos in natura, com um potencial muito superior às ofertas industrializadas (Mossmann \& Teo, 2017). Também propicia ganhos em termos de geração de emprego e renda para as famílias de agricultores, por meio de suas associações e cooperativas, que passam a se apropriar da renda que antes era direcionada para os atravessadores e para as grandes redes de distribuição de alimentos. Além dos ganhos pela relação direta, a política de compras avançou por simplificar a relação para as aquisições, considerando que parte do afastamento desses produtores do mercado público se deu em virtude da complexidade das regras das compras públicas. Para Mossmann e Teo (2017):

. . essa legislação colocou em cena inovações relevantes no âmbito da simplificação das compras públicas e do fortalecimento da agricultura familiar. Sob esta perspectiva, o PNAE passa a representar uma via para os agricultores familiares comercializarem seus produtos, constituindo um novo e expressivo mercado institucional (p. 32).

A Resolução FNDE n. 38 (2009) determinou que a compra direta da agricultura familiar deveria priorizar os produtores locais dos municípios que realizam as contratações e autorizou que, nos casos em que isso não fosse possível, a compra priorizasse os agricultores da mesma "região, do território rural, do estado e do país, nesta ordem de prioridade" (Resolução FNDE n. 38, 2009, Artigo $\left.18^{\circ}, \S 4^{\circ}\right)$. Outra característica marcante dessa regulamentação foi a exigência de que os lotes de compras deveriam ser divididos em tantas parcelas quanto possível, "considerando a sazonalidade e as peculiaridades da produção da agricultura familiar" (Resolução FNDE n. 38/2009, Artigo 19º, IV) com o objetivo de favorecer o máximo de produtores existentes. Já a Resolução FNDE n. 26 (2013) avançou por explicitar melhor a operação do chamamento público, especialmente no que diz respeito às regras de preferência e de desempate.

Assim, a Lei n. 11.947 (2009) e suas regulamentações apresentaram um grande desafio de implementação para todos os entes federados que recebem recursos do FNDE, fazendo com que tivessem que organizar suas burocracias para compreender e operar os chamamentos públicos. Outro desafio em termos de implementação seria a comunicação da nova possibilidade de fornecimento para os agricultores familiares, assim como a organização das logísticas para recebimento dos produtos e entrega nas escolas, considerando que o número de fornecedores seria maior do que aquele que existia quando as aquisições eram feitas em lotes fechados nos processos de licitação, tendo um único ou poucos fornecedores para o município. 
O estudo de caso no qual este artigo se baseou (Jesus, 2014) analisou a experiência de compra direta da agricultura familiar no município de São Bernardo do Campo, no período de sua implementação (de 2009 a 2012), a partir de uma análise qualitativa e por meio de pesquisa de campo. Para o estudo, foi realizada a sistematização de elementos verificados na revisão bibliográfica como essenciais para a compreensão das experiências de uso do poder de compra de Estado, a fim de investigar sua relação com a promoção do desenvolvimento local.

O instrumento elaborado para análise do caso buscou compreender os seguintes eixos do objeto de estudo: (I) caracterização do município (perfil econômico, social, educacional etc.); (II) caracterização da experiência (tipo de uso do Poder de Compra do Estado; objetivos/ razões que justificam a prática; período de duração da experiência; orçamentos [anual e mensal]; parcerias; origens dos recursos; responsáveis; ações de monitoramento/avaliação interna; quantidade de atores beneficiados); (III) ações destinadas à realização da experiência (normatização (leis/decretos/portarias); alterações nos processos de compras; estratégias de divulgação/sensibilização dos fornecedores; sistema de seleção de fornecedores; capacitação de pessoal responsável pela implementação da ação; apoio/instruções aos fornecedores); (IV) resultados da implementação (qualidade dos bens/serviços adquiridos; cumprimento dos prazos de entrega; atingimento do público-alvo pretendido); (V) impactos para a prefeitura (variação da verba obtida por fornecedor; variação da qualidade de produção/serviço; variação no período de fornecimento para o setor público); e (VI) impactos para as organizações beneficiadas (variação da renda obtida por fornecedor; variação na capacidade administrativa; variação das condições de trabalho; variação na qualidade dos bens/ serviços ofertados; variação na capacidade de investimento; variação na geração de impactos ambientais).

Para compor as informações requeridas pelo instrumento de análise do caso, foram realizadas pesquisas em fontes de dados oficinais, tais como o FNDE, Instituto Brasileiro de Geografia e Estatística (IBGE, 2017), Portal da Transparência da Prefeitura de São Bernardo do Campo, entre outras fontes; análise dos processos administrativos das compras realizadas com a agricultura familiar no município e a partir de entrevistas semiestruturadas realizadas com membros da Secretaria de Educação e Cultura da Prefeitura de São Bernardo do Campo (a secretária municipal e outros seis membros da Divisão de Alimentação Escolar) e com membros de sete entre as 22 cooperativas e associações que eram fornecedoras do município, na sede dessas organizações (cooperativas e associações) de agricultura familiar que forneceram para o município de São Bernardo do Campo entre 2010 e 2013. Também foram solicitadas informações adicionais a partir do canal que atende à Lei de Acesso à Informação (Lei n. 12.527, de 18 de novembro de 2011).

A pesquisa demostrou que o município de São Bernardo do Campo está entre os primeiros a concluírem a implementação da compra direta, conseguindo, inclusive, destinar $100 \%$ dos recursos do PNAE para a agricultura familiar. $O$ município está localizado no estado de São Paulo, na região 
metropolitana da cidade de São Paulo. Possui aproximadamente 765.463 habitantes, de acordo com dados de 2010 do IBGE, e $409,478 \mathrm{~km}^{2}$ de extensão segundo a mesma fonte, além de possuir a sétima maior receita orçamentária entre os municípios brasileiros. Mas, em contraste com a atuação dos setores industrial e de serviços, a participação agropecuária do município é praticamente inexpressiva. De acordo com o IBGE, em 2006, o município de São Bernardo do Campo possuía apenas 29 unidades agropecuárias, distribuídas em 1,78 km².

Também foi verificado que a motivação para implementar a compra direta da agricultura familiar não surgiu da necessidade de fomentar a agricultura no próprio município. Não havia organizações com Declaração de Aptidão (DAP) do Programa Nacional de Agricultura Familiar (Pronaf) em São Bernardo do Campo, tendo os agricultores do município que se interessaram em vender para a merenda escolar que se associarem à organização mais próxima, a Cooperativa dos Agricultores Familiares de Guarulhos e Região (Agroverde), pois estavam em número muito pequeno para estabelecer uma organização própria.

De maneira sintética, é possível afirmar que o histórico profissional dos atores públicos responsáveis pela implementação da compra direta da agricultura familiar foi muito favorável no caso de São Bernardo do Campo. O prefeito do município nos mandatos 20092012 e 2013-2016, Luiz Marinho (PT), foi presidente do Conselho Nacional de Segurança Alimentar e Nutricional (Consea) entre 2003 e 2004, quando auxiliou na coordenação das ações para o crédito à agricultura familiar. Em 2005, assumiu o Ministério do
Trabalho e Emprego e, em 2007, o Ministério da Previdência Social. Enquanto ministro, participou da elaboração das ações do Programa "Fome Zero", entre as quais estava a diretriz de conectar a produção da agricultura familiar com o consumo da merenda escolar. A Secretária Municipal de Educação, Cleuza Repulho, trabalhava no FNDE e participou das atividades que concretizaram a compra direta da agricultura familiar. Por fim, a figura que mais se mostrou central para a implementação da experiência foi a do então funcionário João Tadeu, que participou diretamente da elaboração do Programa "Fome Zero" em 2003, a convite do então ministro extraordinário João Graziano da Silva, na pasta de Segurança Alimentar e Combate à Fome. No período, contribuiu com a formulação do PAA.

Nos anos de 2000 a 2012, os repasses do PNAE representaram, em média, $27 \%$ do orçamento da merenda escolar no município de São Bernardo do Campo, sendo o restante do orçamento composto por recursos do tesouro do município. Antes da implementação da experiência, em 2009, nenhum agricultor familiar, individualmente ou por meio de organizações coletivas, fornecia diretamente para a merenda escolar no município de São Bernardo do Campo. Em 2010, o município destinou $28 \%$ dos recursos do PNAE para a agricultura familiar, passando em 2011 para 86,4\%, em 2012 para 87,1\% e em 2013 para $86,5 \%$. Além do valor dos gêneros em si, as cooperativas recebem um acréscimo de até $33 \%$ sobre o preço dos produtos para custear as despesas de frete e embalagem.

Nos três anos da experiência, foram selecionadas 22 organizações. Em sua maioria, as organizações estão sediadas em municípios 
próximos à região metropolitana da cidade de São Paulo. As demais se encontram no interior do Estado de São Paulo, ou em distintos estados do Sul do País.

Para implementar a experiência, foi necessário enfrentar barreiras à transição. A entrevista realizada com o ex-funcionário João Tadeu revelou que houve uma forte resistência das nutricionistas que atuavam no período em adquirir da agricultura familiar, sendo necessário um longo esforço de convencimento para demonstrar a qualidade $e$ a diversidade dos produtos oferecidos por essas organizações. O setor jurídico do município também precisou ser convencido de que não descumpriria a Lei n. 8.666/93 ou nenhuma outra legislação.

No início da implementação da experiência, também houve certa relutância das merendeiras das escolas do município na aceitação dos produtos da agricultura familiar, pois nem todos atendiam aos padrões aos quais elas estavam acostumadas quando as compras eram feitas exclusivamente de atacadistas. Alguns produtos oriundos da agricultura familiar são entregues em tamanhos diferentes uns dos outros, o que dificulta seu manejo e preparo. Para solucionar essa questão, a prefeitura fez uma ação de sensibilização inicial, sorteando 70 funcionárias entre as merendeiras das escolas do município para participarem de um conjunto de excursões que as levou para conhecer cooperativas de agricultura familiar, ajudando-as a compreender e a se sensibilizar com as dificuldades e fragilidades institucionais dos pequenos produtores. Além disso, a experiência serviu para que os agricultores pudessem ouvir diretamente das cozinheiras queixas e sugestões sobre como os produtos devem ser entregues.

Duas vezes por ano, durante as formações realizadas com os funcionários das escolas, continua a haver sorteio de um grupo de cerca de 5 a 10 merendeiras por vez para visitas nas cooperativas de agricultura familiar. A questão da agricultura familiar sempre é reforçada nas formações, por meio de palestras de membros das organizações de agricultores familiares e da apresentação de vídeos elaborados nas visitas às sedes das organizações.

Especificidade e realizações da experiência de São Bernardo do Campo

Assim que a Lei Federal n, 11.947 (2009) foi promulgada, uma equipe de funcionários da Divisão de Alimentação Escolar foi designada para localizar organizações de agricultores familiares que pudessem fornecer os $30 \%$ requisitados pelo FNDE e descobrir como realizar as chamadas públicas, as compras e os pagamentos. Em seguida, foi iniciado o processo de criação da Comissão de Implementação, Acompanhamento e Execução da Aquisição de Produtos da Agricultura Familiar Rural para a Merenda Escolar do Município de São Bernardo do Campo, doravante denominada apenas de Comissão, criada pelo Decreto n. 17.064 (2010).

A Comissão, formada por membros dos distintos órgãos responsáveis pelas decisões da merenda, ficou responsável por planejar as quantidades e os itens a serem solicitados nas chamadas públicas, garantindo que o solicitado representasse o disponível nas cooperativas já contatadas. Ela também teve que estudar os procedimentos legais para a 
elaboração da chamada pública e dos contratos com as cooperativas. A Comissão também ficou responsável por manter contato com as organizações de agricultores familiares e tomar a decisão sobre quais cooperativas credenciadas poderiam firmar contratos e definir os pagamentos.

Para garantir que houvesse organizações com DAP Jurídica que viessem a fazer parte da chamada pública, membros da Comissão em 2010 tiveram que avisar as cooperativas e associações mais próximas do município sobre a existência da chamada pública, e informar de quais documentos elas precisariam para estarem aptas a vender para a prefeitura. De acordo com a supervisora Vanessa, sem que a prefeitura de São Bernardo do Campo custeasse as visitas até a sede das organizações (translado, alimentação e hospedagem, quando necessário), tanto nos períodos de sensibilização quanto para contínuas visitas de avaliação e resolução de conflitos, não teria sido possível adquirir da agricultura familiar nas quantidades e com a qualidade atualmente atingida.

$\mathrm{Na}$ ocasião, os funcionários analisavam os documentos que os agricultores possuíam e orientavam quais ações deveriam ser feitas para que eles pudessem passar a vender para a prefeitura, além de realizar checagem de área de plantio, verificação das estruturas das organizações, da documentação dos agricultores e da qualidade dos produtos. $\mathrm{A}$ visita a campo também serviu para descobrir quais eram os produtos oferecidos pelos agricultores familiares da região, de modo a adequar o cardápio aos itens disponíveis e definir as quantidades a serem solicitadas no edital das chamadas públicas.

Além disso, para conseguir realizar a com- pra dos agricultores familiares, especialmente nos primeiros anos de chamada pública, foi preciso São Bernardo do Campo ser mais flexível no processo de contratação, pois as cooperativas ainda não possuíam uma capacidade de produção suficiente nem a capacidade de entregar todos os documentos prontamente. A Comissão optou por não aplicar sanções em todos os casos em que houvesse atrasos ou problemas com a entrega dos produtos, pois, dada a fragilidade institucional das organizações de agricultores familiares, a aplicação de sanções levaria a prejuízos financeiros percentualmente tão altos, em relação aos recursos das organizações, que a manutenção da entrega deixaria de ser possível.

Todos esses esforços permitiram que São Bernardo do Campo conseguisse adquirir quase a totalidade dos recursos do PNAE de organizações de agricultores familiares. Esses esforços levaram a uma revisão do planejamento e da gestão dos contratos da merenda escolar, o que permitiu um cardápio mais diversificado. As compras da agricultura familiar, associadas às transformações no cardápio do município, permitiram reduzir a incidência de açúcar, gorduras, conservantes e alimentos embutidos no cardápio da merenda escolar. Até a publicação deste estudo, nenhuma das bebidas oferecidas aos alunos (sucos, leite, entre outras) contém açúcar. $O$ fato de a qualidade das frutas e verduras ter melhorado também colaborou para que os alunos consumissem mais esses produtos.

O paradigma do preço na implementação da experiência

Até este momento, todas as ações voltadas 
à implementação da experiência foram baseadas no diálogo e organizadas de modo a favorecer os agricultores. Especialmente porque, por meio das visitas às organizações, os membros da Comissão conheceram a realidade da vida dos agricultores e adquiriram um senso de responsabilidade com o sucesso da experiência. Contudo, a saída do funcionário João Tadeu provocou uma ruptura no favorecimento dado aos agricultores em 2010 e 2011.

Enquanto o funcionário Tadeu conduziu o processo, a chamada pública deveria servir apenas para notificar as organizações de agricultores familiares sobre a oportunidade de venda, informando as quantidades e os preços praticados no mercado. As organizações, por sua vez, deveriam apresentar um projeto de venda, informando seus custos, quantidades de interesse e preços. Feito isso, caso houvesse mais de uma organização interessada em vender o mesmo produto, a entidade compradora deveria utilizar os critérios previstos na Resolução FNDE n. 38 (2009) para estabelecer o desempate. A resolução afirmava que deveria ser dada prioridade para os produtores locais, seguidos pelos da região, do estado e do País, nessa ordem. Também indicava que deveria ser dada prioridade para os produtores de itens orgânicos, para os assentados da reforma agrária, quilombolas e indígenas. No entanto, a redação não esclarecia o que, de fato, deveria ser uma chamada pública, e relatava de maneira confusa qual deveria ser a ordem de prioridade.

Na prática, os conflitos eram negociados entre todos os interessados, e todas as organizações que se inscreveram nas chamadas públicas de 2010 e 2011 foram selecionadas para vender para São Bernardo do Campo. No entanto, com a saída do funcionário Tadeu, o preço passou a ser utilizado como critério final de desempate. De acordo com as cooperativas entrevistadas, é o que também acontece em grande parte das prefeituras que adquirem da agricultura familiar. $\mathrm{Na}$ resolução de 2009, não houve nenhuma referência à utilização do preço como critério de desempate. Ainda assim, não havia sido indicada uma solução para os casos em que os critérios de desempate apontados não fossem suficientes para a seleção, o que permitiu que as prefeituras aproveitassem para conseguir preços mais vantajosos para o município. Atraídas pelo volume e constância das vendas para São Bernardo do Campo, as organizações de agricultores familiares competiam entre si para oferecer o menor preço. No entanto, como possuíam pouco conhecimento sobre a estrutura de vendas para o setor público, acabaram por operar em prejuízo, uma vez que as quantidades realmente adquiridas por São Bernardo do Campo acabaram por ser inferiores ao que havia sido contratado, tendo em vista adequações dos cardápios e cortes do orçamento do município ao longo do ano.

As organizações que forneciam hortaliças e frutas foram as mais prejudicadas, pois dependiam de tabelas de preço fixas para determinar seus preços, e, tendo adotado percentuais muito baixos, chegaram a não ter como cobrir seus custos. Em alguns casos, as organizações optaram por não entregar ao município para não operar em prejuízo.

\section{O PAPEL POLÍTICO DO FUNCIONÁRIO PÚBLICO NA IMPLEMENTAÇÃO DE PO- LÍTICAS PÚBLICAS}


A escolha do município de São Bernardo do Campo para o estudo de caso mostrou-se bastante apropriada, já que a experiência reúne um conjunto de medidas imprescindíveis para o sucesso das compras diretas da agricultura familiar, ao mesmo tempo que apresenta questões a serem melhoradas, configurando um caso representativo da implementação de diretrizes federais em contexto municipal.

Os entrevistados na prefeitura de São Bernardo do Campo e nas organizações de agricultores familiares sustentaram que, se não houvesse sido implementada a Lei 11.947 (2009) e feitos os esforços de mobilização de adequação das regras para os agricultores familiares, nenhum desses grupos seria hoje fornecedor da prefeitura de São Bernardo do Campo. Ainda assim, especialmente para os produtores de grãos e de hortifrúti, se não houver uma intensificação da governança nas questões logísticas e de preço, a tendência é que seja cada vez mais difícil manter as compras.

No caso de São Bernardo do Campo, os principais perfis envolvidos com a implementação, tanto os políticos quanto os dirigentes públicos, estavam alinhados $\mathrm{e}$ comprometidos com o favorecimento aos agricultores familiares, para além dos procedimentos burocráticos estabelecidos na legislação vigente. Sem o acompanhamento adicional realizado por toda a equipe do município, dificilmente seria possível atingir os resultados obtidos a partir da ação discricionária dos funcionários envolvidos.

O servidor Tadeu exerceu o papel de dirigente público descrito por Bonis e Pacheco (2010), utilizou-se de criatividade e inovação para atingir os resultados almejados, com benefícios para as cooperativas e, sobretudo, para a merenda escolar dos estudantes. Associados à diretriz federal, o empenho e os recursos mobilizados pelo dirigente público foram capazes de superar a inércia da máquina pública.

Ainda assim, o comprometimento do alto escalão e do dirigente público não teria sido suficiente para o sucesso da implementação, considerando todo o conjunto do desenho da política (benefício para os agricultores familiares e para a merenda escolar) se não tivesse sido alcançada a sensibilização da burocracia que opera o cotidiano da política. Esses atores realizaram um conjunto variado de ações que não estavam previstas em lei, mas sem as quais as aquisições da agricultura familiar nas quantidades e com a qualidade atuais não seria possível. No início da implementação, houve um empenho explicito em garantir que uma grande quantidade de organizações de agricultores familiares fosse fornecedora da merenda escolar, e que esse fornecimento possibilitasse ganhos significativos para os agricultores beneficiados. Para tanto, houve a criação de uma série de instrumentos para o planejamento dessas compras. A criação de uma comissão intersetorial para lidar com as demandas que esse desafio imporia foi uma medida central. Nos primeiros anos de implementação, mais precisamente entre 2009 e 2011, favorecer a agricultura familiar, ainda que as organizações não pertencessem às fronteiras administrativas do município, foi o principal objetivo da implementação da experiência.

Esse objetivo refletiu-se na redução das exigências burocráticas, no auxílio técnico fornecido às organizações que se apresen- 
taram como potenciais fornecedores, na busca ativa por organizações fornecedoras e especialmente nos encontros estabelecidos entre os dois grupos: burocracia pública e organizações de agricultores familiares. Esses encontros construíram dois importantes ganhos para o alcance das compras da agricultura familiar nas quantidades e na qualidade atualmente praticadas. O primeiro deles foi a sensibilização da burocracia responsável pela implementação da experiência (a Divisão de Alimentação Escolar e a Comissão) para as condições de vida e de trabalho dos agricultores familiares. Permitiu que esses atores da burocracia se certificassem da importância da experiência, identificassem o apoio que seria necessário para tornar a implementação da Lei n. 11.947 (2009) possível e adquirissem um senso de responsabilidade sobre a implementação da experiência.

O segundo grande ganho desses encontros foi o fortalecimento da capacidade das organizações de agricultores familiares em vender para a prefeitura. Nos primeiros anos, nenhuma das organizações tinha vendido para prefeituras por meio das regras do PNAE, havia desconfianças acerca da garantia do pagamento e dúvidas sobre como deveriam atuar, questões que foram solucionadas pela realização de reuniões.

No entanto, as entrevistas com os atores envolvidos na implementação da experiência mostraram que houve um declínio na disposição da prefeitura de São Bernardo do Campo em favorecer as organizações de agricultores familiares. A aplicação de sanções em vez da resolução de conflitos por meio do diálogo tornou-se mais frequente, e a resolução de questões para as quais antes houve um empenho em benefício dos agricultores (como o preço de referência e a redução de questões burocráticas) passou a ser menos frequente. Houve uma série de prejuízos financeiros para as cooperativas de hortifrúti e o encerramento de contratos que poderiam ter sido renovados. Cada vez mais, o tratamento dado às organizações de agricultores familiares aproximou-se do oferecido às fornecedoras tradicionais.

Assim, a saída do funcionário Tadeu e o desgaste gerado pela rotina ao longo da experiência parecem ter feito com que essa disponibilidade de superar as exigências legais para favorecer os agricultores familiares tenha caído. Por desconhecer a realidade das cooperativas de agricultores familiares e priorizar uma economia de recursos não condizente com a características dessas organizações, os próximos servidores responsáveis por implementar a política colocaram em risco todo o sucesso anterior da implementação.

\section{CONSIDERAÇÕES FINAIS}

O objetivo deste artigo foi discutir o papel dos atores governamentais na implementação de políticas públicas, por meio da análise da experiência de São Bernardo do Campo na implementação da Lei 11.947 (2009). $\mathrm{O}$ artigo discutiu a centralidade das ações de implementação para o cotidiano dos municípios, suas principais características e a relevância do papel dos atores governamentais para o seu sucesso.

Como observado no caso de São Bernardo do Campo, a implementação demanda um grande esforço de inovação para superar questões que não foram previstas pelas 
diretrizes impostas pelo governo federal. A inexistência, não formalização ou fragilidade institucional das cooperativas, a resistência a utilizar mecanismos de compra distintos dos padrões de licitações consolidados na administração pública brasileira, a desconfiança sobre a qualidade dos produtos ofertados pela agricultura familiar e o desconhecimento sobre a estrutura produtiva agrária nacional, assim como uma simples tendência à inércia, foram barreiras inesperadas impostas ao processo de implementação que requereram a ação inventiva e politicamente orientada do servidor alocado como dirigente público. Sem esses esforços empreendidos pelo ator-chave, a implementação poderia não ter sido bem-sucedida, como ficou comprovado pela alteração dos rumos da experiência após a saída do funcionário Tadeu.

A decisão por aproximar as nutricionistas, merendeiras e operadores das chamadas públicas da realidade das cooperativas de agricultores também foi crucial não apenas para sensibilizá-los da importância da política, mas para que pudessem antecipar, compreender e estabelecer estratégias de superação às questões que limitariam o sucesso da implementação.

Por outro lado, após a saída do servidor que atuava como dirigente público, um conjunto de questões que poderiam ser resolvidas caso houvesse a mesma disposição do começo da experiência acabou se sobrepondo, levando ao encerramento de contratos com algumas organizações: tabelas de preços, período de realização das chamadas públicas, burocracia etc. Além disso, a desmobilização das cooperativas acabaria por limitar a economia que já tinha sido al- cançada com a saída dos atravessadores e das empresas distribuidoras de merenda da cadeia de custos desses recursos.

Assim, a experiência analisada a partir da bibliografia discutida neste artigo nos permite concluir que o posicionamento político dos funcionários públicos infere diretamente na sua capacidade de realização no trabalho, e mais, nos resultados das políticas públicas. Ao estarem diretamente envolvidos na implementação, são capazes de ressignificar atos normativos para que se adéquem à realidade vivenciada no País. Ao falarmos do contexto local, esse papel torna-se ainda mais importante, dado que a maior parte dos municípios ainda conta com uma estrutura de administração e gestão insuficiente.

\section{REFERÊNCIAS}

Barrett, S. (2004). Implementation studies: Time for a revival? Public Administration, 82(2), 249-262. doi:10.1111/j.00333298.2004.00393.x

Bonis, D. de, \& Pacheco, R. S. (2010). Nem político nem burocrata: $O$ debate sobre o dirigente público. In F. Abrucio, M. R. Loureiro, \& R. S. Pacheco (Orgs.), Burocracia e política no Brasil: Desafio para o estado democrático no século XXI (Vol. 1, pp. 273-295). Rio de Janeiro, RJ: Editora da Fundação Getulio Vargas.

Decreto n. 17.064, de 14 de janeiro de 2010. (2010). Dispõe sobre a criação da comissão de implantação, acompanhamento e execução da aquisição de produtos da agricultura familiar e do empreendedor familiar rural para a merenda escolar de São Ber- 
nardo do Campo. Recuperado de https:// leismunicipais.com.br/a/sp/s/sao-bernardo-do-campo/decreto/2010/1707/17064/ decreto-n-17064-2010-dispoe-sobre-a-criacao-da-comissao-de-implantacao-acompanhamento-e-execucao-da-aquisicao-de-produtos-da-agricultura-familiar-e-do-empreendedor-familiar-rural-para-a-merenda-escolar-do-municipio-de-sao-bernardo-do-campo?q=agricultura\%20familiar

Farah, M. F. S. (2000). Governo local, políticas públicas e novas formas de gestão pública no Brasil. Organizações \& Sociedade, 7(17), 59-86. doi:10.1590/ S1984-92302000000100005

Instituto Brasileiro de Geografia e Estatística. (2017). Cidades: São Bernardo do Campo. Recuperado de http://cidades.ibge.gov. $\mathrm{br} / \mathrm{xtras} /$ perfil.php?codmun $=354870$

Jesus, D. de F. B. (2013). Perspectivas e controvérsias sobre o uso do poder de compra do estado a partir da experiência brasileira. Foro Bienal Iberoamericano de Estudios del Dessarrollo, Santiago, Chile. Recuperado de http://riedesarrollo.org/memorias/2013/ mesas/mesa2/2.I.2\%20Deloise\%20de\%20 Fatima\%20Bacelar_Perspectivas\%20e\%20 controversias.pdf

Jesus, D. de F. B. (2014). Limites e possibilidades do uso do poder de compra do estado em favor do desenvolvimento sustentável local e regional: Estudo de caso da implementação da Lei Federal $n$. 11.947/2009 no Munic ípio de São Bernardo do Campo - 2009 a 2013 (Dissertação de Mestrado, Centro de Engenharia, Modelagem e Ciências Sociais Aplicadas (CECS) da Universidade Federal do ABC, SP).
Kingdon, J. (1984). Agendas, alternatives, and public policies. Boston, USA: Little, Brown.

Lei $n^{\circ}$. 12.527, de 18 de novembro de 2011. (2011). Regula o acesso a informações previsto no inciso XXXIII do art. 5o, no inciso II do $\S 30$ do art. 37 e no $\S 20$ do art. 216 da Constituição Federal; altera a Lei no 8.112, de 11 de dezembro de 1990; revoga a Lei no 11.111, de 5 de maio de 2005, e dispositivos da Lei no 8.159 , de 8 de janeiro de 1991; e dá outras providências. Recuperado de < http://www.planalto.gov.br/ccivil_03/_ ato2011-2014/2011/lei/l12527.htm>.

Lei n. 11.947, de 16 de junho de 2009. (2009). Dispõe sobre $o$ atendimento da alimentação escolar e do Programa Dinheiro Direto na Escola aos alunos da educação básica; altera as Leis n. 10.880, de 9 de junho de 2004, 11.273, de 6 de fevereiro de 2006, 11.507, de 20 de julho de 2007; revoga dispositivos da Medida Provisória no 2.178-36, de 24 de agosto de 2001, e a Lei n. 8.913, de 12 de julho de 1994; e dá outras providências. Recuperado de http://www.planalto.gov.br/ccivil_03/_ato2007-2010/2009/lei/l11947.htm

Mossmann, M. P., \& Teo, C. R. P. A. (2017, Abril/Junho). Alimentos da agricultura familiar na alimentação escolar: Percepções dos atores sociais sobre a legislação e sua implementação. Interações (Campo Grande), 18(2), 31-44. doi:10.20435/inter.v18i2.1391

Resolução/CD/FNDE n. 26, de 17 de junho de 2013. (2013). Dispõe sobre o atendimento da alimentação escolar aos alunos da educação básica no âmbito do Programa Nacional de Alimentação Escolar - PNAE. Fundo 
Nacional de Desenvolvimento da Educação. Recuperado de http://www.fnde.gov. $\mathrm{br} /$ fnde/legislacao/resolucoes/item/4620-resolu\%C3\%A 7\%C3\%A3o-cd-fnde-n\%C2\%BA-26,-de-17-de-junho-de-2013

Resolução/CD/FNDE n. 38, de 16 de julho de 2009. (2009). Dispõe sobre o atendimento da alimentação escolar aos alunos da educação básica no Programa Nacional de Alimentação Escolar - PNAE. Fundo Nacional de Desenvolvimento da Educação.
Recuperado de http://www.fnde.gov.br/fnde/ legislacao/resolucoes/item/3341-resoluCao-cd-fnde-BA-38

Silva, J. G., Grossi, M. E., \& França, C. G. (Orgs.). (2010). Fome Zero: A experiência brasileira. Brasília, DF: MDA.

Weber, M. (1982). Ensaios de sociologia (5a ed.). Rio de Janeiro, RJ: LTC. 